\title{
Agentes comunitários de saúde no CONTEXTO DA IMPLANTAÇÃO DE GRANDES OBRAS DE INFRAESTRUTURA: O CASO DA hidrelétrica Belo Monte, Altamira-PA
}

\author{
Márcia GRISOTTI \\ Dinar Duarte de VASCONCELOS** \\ Emilio Frederico MORAN $N^{* * *}$ \\ Geysiane Costa e SILVA ${ }^{* * *}$
}

\begin{abstract}
RESUMO: O artigo analisa a percepção dos agentes comunitários de saúde (ACS) sobre o desempenho de suas atividades no contexto de implantação da Usina Hidrelétrica Belo Monte em Altamira-PA. Essa obra intensificou os processos econômicos e sociais e evidenciou os desafios do trabalho comunitário. Através de grupos focais e questionários aplicados aos ACS, em 2015, analisamos a percepção dos ACS que trabalham na região impactada pela usina sobre: o reconhecimento e satisfação com seu trabalho; a identificação de áreas de risco e de famílias expostas à situação de riscos; as dificuldades encontradas durante as visitas domiciliares; e os impactos nos indicadores de saúde trazidos pelo empreendimento Belo Monte. $\mathrm{O}$ artigo pretende contribuir na proposição de estratégias futuras que fomentem a melhor incorporação desses agentes no processo de identificação e mitigação dos impactos causados por grandes empreendimentos, dada a sua proximidade e experiência cotidiana com os problemas da cidade e de seus residentes.
\end{abstract}

PALAVRAS-CHAVE: Atenção básica em saúde. Agentes comunitários de saúde. Hidrelétrica Belo Monte. Percepção de impactos.

\footnotetext{
UFSC - Universidade Federal de Santa Catarina. Departamento de Sociologia e Ciência Política. Florianópolis - SC - Brasil. 88040-970 - marcia.grisotti@ufsc.br. https://orcid.org/0000-0003-0389-7100 "* UEPA - Universidade do Estado do Pará. Departamento de Ciências do Movimento Humano. Belém PA - Brasil. 66087-310 - divasconcelos@uepa.br. https://orcid.org/0000-0002-6889-1749

*** Michigan State University. Center for Systems Integration and Sustainability. East Lansing - MI - USA. 48823 - moranef@msu.edu. https://orcid.org/0000-0001-5153-545X

**** UEMA - Universidade Estadual do Maranhão. BIONORTE - Rede de Biodiversidade e Biotecnologia na Amazônia Legal. Museu Paraense Emílio Goeldi. São Luis - MA - Brasil. 65.055-310 geysianecosta18@hotmail.com. https://orcid.org/0000-0002-7617-0765
} 


\section{Introdução}

A lei $\mathrm{n}^{\circ} 11.350$ de 5 de outubro de 2006 , em seu art. $3^{\circ}$, estabelece como atribuição do agente comunitário de saúde (ACS), o exercício de atividades de prevenção de doenças e promoção da saúde, mediante ações domiciliares ou comunitárias, individuais ou coletivas, desenvolvidas em conformidade com as diretrizes do Sistema Único de Saúde (SUS) e sob supervisão do gestor municipal, distrital, estadual ou federal (BRASIL, 2006) ${ }^{1}$.

Desde a criação do Programa de Agentes Comunitários de Saúde (PACS), em 1991, enquanto política de fortalecimento do Sistema Único de Saúde (SUS), uma série de atividades foram sendo destinadas aos ACS. Embora não seja objetivo desse artigo realizar um estudo sobre as origens e o estado atual do exercício da profissão, a análise das pesquisas realizadas com os ACS nos permitiu identificar o caráter contextual da produção de conhecimento sobre esse sujeito social, ou seja, de como essa produção está relacionada ao contexto histórico, marcado pelas mudanças conjunturais, políticas e econômicas do país.

Os primeiros trabalhos refletiam o contexto do ainda incipiente processo de implantação do SUS e da busca por referências teóricas para auxiliar a compreensão da relação Estado/Sociedade, especialmente quanto à experiência da municipalização, da descentralização do setor saúde e dos desafios para efetivar a participação e controle social nas políticas sociais, diante dos resquícios de uma "cultura autoritária", termo densamente estudado por Cardoso, 1982; Schwartzman, 1982; O’Donnell, 1973. Assim como centravam a análise na organização e funcionamento do sistema de saúde no Brasil e os dilemas relacionados com as necessárias adequações do papel dos ACS às diretrizes do SUS. Há um consenso, repetidamente reiterado na literatura, sobre as fontes inspiradoras do PACS, como as experiências do Programa de Interiorização de Ações de Saúde e Saneamento (PIASS), em 1976, e o Programa Nacional de Serviços Básicos de Saúde, em 1982, mostrando, mais uma vez, certas continuidades no âmbito da história das políticas de saúde no Brasil.

Posteriormente, um vasto volume de publicações emergiu dedicado à identificação dos problemas encontrados para a viabilização de seu trabalho, em diversas regiões do país, o qual colocava em xeque os limites de sua atuação. Enquanto era esperado que o ACS desempenhasse o papel de mediador entre os saberes técnicos e populares, entre a equipe de saúde e a comunidade, os estudos recentes têm provocado reflexões sobre em quais circunstâncias vem se consolidando

1 O Projeto de Lei da Câmara (PLC) nº 56/2017, alterou partes dessa lei e redefiniu suas atribuições, nível de qualificação, jornada e condições de trabalho dos ACS e dos agentes de combate às endemias. Novas pesquisas serão necessárias para avaliar as consequências dessa mudança. 
Agentes comunitários de saúde no contexto da implantação de grandes obras de infraestrutura: o caso da hidrelétrica Belo Monte, Altamira-PA

a prática deste profissional no âmbito dos serviços de saúde na atenção básica (FREITAS, et al., 2015).

Dentre os aspectos reconhecidos como limitantes do trabalho do ACS, destacam-se, os problemas socioeconômicos das famílias, problemas com a saúde do ACS, falta de capacitação e de reconhecimento profissional (MACIAZEKIGOMES et al., 2016), insuficiência de conhecimentos essenciais para o exercício das atividades pelos agentes de saúde e atuação descontextualizada das condições sociais (AVILA, 2011).

Diante do exposto, esse artigo pretende analisar o trabalho dos ACS, porém em uma situação bastante particular: sua atuação no contexto da implantação da usina hidrelétrica de Belo Monte. Essa obra intensificou os processos econômicos e sociais e evidenciou os desafios do trabalho comunitário. Os ACS são atores sociais que, por vivenciarem e compartilharem os problemas da comunidade, poderiam ter sido mobilizados de forma mais ativa no processo de construção da obra, auxiliando possivelmente, na diminuição de alguns dos impactos negativos sofridos pela população rural e urbana. Na primeira parte, analisamos o contexto e as demandas específicas de saúde envolvidas na implantação de uma grande obra de infraestrutura de localização singular, como é o caso da hidrelétrica de Belo Monte.

Na segunda parte, analisamos a percepção dos ACS que trabalham na região impactada pela construção da usina sobre o reconhecimento e satisfação com seu trabalho, sobre a identificação de áreas de risco e de famílias expostas à situação de riscos, sobre as dificuldades encontradas durante as visitas domiciliares, e sobre como eles avaliam a comunidade no qual atuam em relação à: 1) o que as pessoas da comunidade mais reclamam dos serviços de saúde; 2) quais outras terapias ou curas as pessoas utilizam, relatadas durante as visitas domiciliares; 3 ) problemas com as pessoas ou famílias, e de conflitos entre os membros da família em visitas no domicilio; 4) algum tipo de preconceito, costume, ideias religiosas que poderiam interferir na saúde da população. E, na terceira parte, analisamos a percepção dos ACS sobre os impactos nos indicadores de saúde trazidos pelo empreendimento Belo Monte.

Esperamos contribuir, com esse artigo, na proposição de estratégias futuras que fomentem a melhor incorporação desses agentes no processo de identificação e mitigação dos impactos em grandes empreendimentos, dada a proximidade e experiência cotidiana com os problemas da cidade e de seus residentes.

\section{Metodologia}

De um total de 124 ACS na área de estudo, 28 eram ACS rurais e 96 eram ACS urbanos. Compuseram a amostra, 53 ACS, sendo 25 urbanos e 28 rurais, que 
correspondia a $26 \%$ e $100 \%$ do universo total, respectivamente. Utilizou-se para coleta de dados, questionários formulados por nossa equipe de pesquisa, que foram aplicados antes do início de uma atividade de capacitação profissional, realizada pela Secretaria de Saúde de Altamira no ano de 2015, para cada categoria (uma com ACS urbanos e outra com ACS rurais). A amostra foi composta, portanto, com os ACS que se disponibilizaram a responder o questionário antes dessas reuniões. Todos os que estavam na reunião responderam ao questionário com 27 perguntas fechadas e 20 abertas, que demorou em torno de 1 hora para ser respondido.

Posteriormente, realizamos dois grupos focais com os ACS, na qual eles foram estimulados a relatarem suas experiências de trabalho. A técnica consistiu no debate coletivo das questões previamente elaboradas pelos pesquisadores: sobre identificação de riscos e conflitos em sua área de atuação, influência de preconceitos ou ideias religiosas que interferiram no trabalho; outras terapias que a comunidade utiliza e os impactos e problemas advindos com a construção de Belo Monte. Com essa técnica foi possível, também, validar algumas perguntas do questionário. No grupo focal com os ACS rurais participaram os mesmos que responderam ao questionário anteriormente, enquanto no grupo focal com os ACS urbanos participaram alguns que responderam ao questionário e outros que não estavam presentes no dia de sua aplicação. Os grupos focais foram gravados e posteriormente transcritos.

Através da tringulação de dados quantitativos e qualitativos (questionário e grupos focais) foi possível analisar a percepção dos ACS sobre as dificuldades na execução de seus trabalhos e as estratégias utilizadas para enfrentarem as contingências que emergem na realização de suas tarefas cotidianas, especialmente no contexto do processo de construção de um grande projeto de desenvolvimento.

\section{A saúde em Altamira-PA no contexto da usina hidrelétrica de Belo Monte}

O processo de construção da usina de Belo Monte acentuou o papel de centralidade da cidade de Altamira em relação às localidades de seu entorno, especialmente por concentrar todo o impacto da expansão do emprego formal devido à proximidade do núcleo urbano em relação aos canteiros de obras e a presença de melhor infraestrutura (NETO; HERRERA, 2016) e por ser receptora de um grande fluxo populacional, provocando expressivas transformações territoriais (LETURCQ, 2016) ${ }^{2}$.

\footnotetext{
2 Para uma análise histórica detalhada das modificações sócioterritoriais da região amazônica, e de Altamira-PA em especial, ver trabalho de Moran (2016).
} 
Agentes comunitários de saúde no contexto da implantação de grandes obras de infraestrutura: o caso da hidrelétrica Belo Monte, Altamira-PA

A cidade de Altamira-PA, possui uma população de 99.075, conforme o último censo realizado no ano de 2010, com estimativa de aumento para $108.382 \mathrm{em}$ 2015 (IBGE, 2015) e de 111.435 para 2017 (IBGE, 2017). Esses valores não previam a contratação de pessoas para trabalhar na obra de Belo Monte que, conforme o relatório apresentado ao IBAMA pela Empresa Norte Energia (NESA), divulgado em fevereiro de 2015, atingiram um pico de 33.115 trabalhadores em junho de 2014; como exposto por Oliveira (2017):

[a] projeção aponta que em Altamira se verifica estabilidade na população, em torno de 140 mil habitantes, sendo que, no cenário esperado, o pico ocorreu em junho de 2014, com 140.190 moradores e na sequência, 139.885 em dezembro de 2014 e 139,455 em junho de 2015. No cenário do alto fluxo, a estabilidade gira em torno de 143 mil habitantes, com pico de 143.515 em junho de 2014, seguido de 143.104 em dezembro e 142.556 em junho de 2015 (OLIVEIRA, 2017, p. 70).

Herrera e Moreira (2016) relataram que a Secretaria de Planejamento do Município de Altamira (SEPLAN) encontrou diferenças significativas no acesso de bens e serviços a partir do processo migratório de Belo Monte. Para eles, os dados do censo demográfico, obtidos pela amostra de domicílios em 2010, não podem estabelecer a projeção da população devido ao grande deslocamento de trabalhadores ligados direta e indiretamente à obra da usina hidrelétrica, pois a SEPLAN estimou uma população no ano de 2012 em 148.224 habitantes, projeção obtida considerando o volume de lixo produzido e o número de atendimentos hospitalares realizados.

Em Altamira-PA, o último censo foi realizado em 2010, havendo previsão para nova coleta em 2015 (i.e. o censo agropecuário), fato que não ocorreu, estando previsto para 2020. O IBGE faz uma série histórica, onde realiza estimativas anuais do aumento populacional a partir da taxa de crescimento, considerando os intervalos entre os censos, não havendo discrepância entre os dados uma vez que estima valores a partir do acumulado. Nessa projeção, Altamira-PA teria uma população de 111.435 para 2017, porém, compreendemos que com o advento Belo Monte esses dados podem estar desconectados da realidade na medida em que a cidade recebeu um grande fluxo migratório em virtude da implantação da Usina Hidrelétrica de Belo Monte, que distribuiu esses trabalhadores em três grandes canteiros de obras: Pimental, Sítio de Canais, e finalmente, Belo Monte.

Demarcamos esse fato porque a prospecção e a efetividade das políticas públicas de saúde dependem essencialmente do diagnóstico real da população residente e dos fluxos migratórios, especialmente porque no setor saúde os investimentos em infraestrutura governamental são realizados em função do número da população 
residente no município. No caso de Altamira-PA, o aumento populacional - especialmente de trabalhadores migrantes que são, na maior parte, dependentes do sistema público de saúde - sobrecarregou os serviços de saúde existentes, enquanto esperava-se a execução das condicionantes para a obtenção da licença de instalação da obra (por exemplo, aumento da infraestrutura hospitalar e demais serviços de saúde), como uma forma concreta de mitigação dos impactos.

No entanto, a expansão dos serviços de saúde através da construção de novas unidades hospitalares não foi devidamente efetivada devido às divergências políticas locais; nem estado, nem município se dispôs a assumir tal responsabilidade, culminando no retardo para a abertura do hospital do Mutirão que passou um ano de portas fechadas e só foi inaugurado mediante a recomendação $n^{\circ}$ 03/2016/ PRM-ATM/GAB1 do Ministério Público Federal, determinando sua imediata abertura em virtude do cenário local.

Esse aumento da demanda populacional inflacionado provocou também aumento das demandas sociais nas mais variadas matizes (alimentação, habitação, saúde, educação, assistência social, segurança pública, entre outras (OLIVEIRA, 2017). Giongo et al. (2015) relatam os problemas vivenciados pelas populações diretamente atingidas que são deslocadas do seu território, o impacto sobre a saúde dos trabalhadores que migram com os projetos e as populações que ficam as margens das grandes construções das hidrelétricas, nas "franjas" do planejamento e que não são contempladas, pois, ficam fora do alcance das políticas compensatórias do empreendimento.

A reorganização urbana, com a inserção de novos bairros para alocar os atingidos em reassentamentos urbanos coletivos (RUC's), provocaram a expansão territorial de cobertura em saúde, culminando na construção de novas unidades básicas de saúde nesses espaços. Todavia, até sua implantação e inserção no sistema, os atendimentos eram vinculados às unidades já cadastradas: uma equipe da unidade ficava atendendo em um espaço provisório adaptado em uma residência para efetivar a prestação de serviços à comunidade, e o ACS era o responsável pela visitação e cadastramento dos novos usuários, sendo o elo entre a unidade básica de saúde com a comunidade.

Uma possível sobrecarga nos serviços de saúde do município de Altamira-PA já havia sido citada no Relatório de Impacto Ambiental (EIA-RIMA). Porém, o relatório aponta que essa sobrecarga seria minimizada através da implantação, pelo empreendedor, de um plano de saúde para os trabalhadores da obra, extensivo a seus dependentes, o qual contribuiria "para desenvolver a medicina complementar dos municípios e tornar os planos de saúde mais atrativos, contribuindo, inclusive, para diminuir o número de usuários do Sistema Único de Saúde" (EIA, 2009, volume 29, p. 97). 
Agentes comunitários de saúde no contexto da implantação de grandes obras de infraestrutura: o caso da bidrelétrica Belo Monte, Altamira-PA

No PBA (2010) de Belo Monte também foi destacado que o EIA-RIMA elaborou um diagnóstico sobre as condições de saúde da população da região que seria afetada pela usina hidrelétrica, evidenciando uma situação epidemiológica típica de regiões pobres, com carência de equipamentos e instalações de saúde pública. O documento enfatiza que na parceria estabelecida com o empreendedor, a Norte Energia se comprometeria a:

[...] construir e equipar unidades de saúde, fornecer transporte para equipes de saúde, contratar médicos e financiar capacitações dos profissionais para comporem as equipes de Saúde dos municípios da AID, necessárias para cobrir $100 \%$ da população atraída pelo empreendimento, conforme os compromissos estabelecidos no PBA. (PBA, 2010, volume III, tomo 2-8, p. 159).

No entanto, apesar de previsto no EIA-RIMA, as demandas de infraestrutura necessárias para absorver e mitigar o aumento populacional não foram executadas no tempo exigido tanto para a licença de instalação, quanto para a licença de operação. Vários documentos mostram a insuficiência dos estudos de impacto e o colapso do sistema de saúde durante o andamento das obras, entre eles, a análise do Painel de especialistas (COUTO; SILVA, 2009) e as Recomendações do Ministério Público Federal (MPF, 2016).

Em 2009, um painel de especialistas, composto por pesquisadores de várias áreas acadêmicas, realizou uma análise crítica do Estudo de Impacto Ambiental do empreendimento, destacando que o EIA-RIMA não incluiu, em seu escopo, um diagnóstico situacional de saúde da população de referência para o empreendimento. De acordo com o painel, "há uma referência a dados secundários, não confiáveis, por não representarem a realidade, o que poderia ser resolvido se o diagnóstico tivesse como metodologia o inquérito epidemiológico da área de influência com a participação da comunidade" (COUTO; SILVA, 2009, p. 88). Uma das conclusões do painel de especialistas é que as alterações ao meio ambiente, provocadas pelo projeto da usina hidrelétrica de Belo Monte, acarretariam consequências maiores do que as previstas e anunciadas no EIA-RIMA (GRISOTTI, 2016).

O parecer do MPF (2016), baseado em visitas locais e documentos, ressaltou: 1) as condições desfavoráveis para a instalação da hidrelétrica tendo em vista a histórica omissão do Estado e a precariedade dos serviços públicos locais (Parecer TCU/2008); 2) a falta de estrutura encontrada na região com relação aos serviços de saúde com déficit de $31 \%$ de leitos hospitalares em relação aos critérios estabelecidos pelo Ministério da Saúde, bem como de 55\% no tocante ao número de médicos necessários para atender a população da região. Além dos baixos e insuficientes gastos em saúde para a manutenção das condições mínimas dos serviços e programas de saúde pública (Análise Técnica do Estudo de Impacto Ambiental da UHE 
Belo Monte - Parecer 114/2009/IBAMA); 3) o custeio do sistema de saúde com infraestrutura ampliada a partir das condicionantes da UHE Belo Monte era um dos maiores desafios para as gestões municipais, especialmente devido ao aumento do fluxo populacional. Este desafio persiste para além do término das obras, tornando-se um problema "invisível” (MAPA DOS CAMINHOS, 2015, p. 24).

O documento menciona também, a morte de crianças indígenas devido ao surto de gripe influenza $\mathrm{H} 1 \mathrm{~N} 1$ que atingiu as aldeias indígenas da região e trouxe à luz a inefetividade das condicionantes de saúde, uma vez que os relatos são de que essas mortes se deram em contexto de colapso do serviço de saúde do município de Altamira devido a instalação da UHE Belo Monte, sem que as condicionantes territoriais e de saúde indígenas fossem implementadas.

Outro fator relevante foram os constantes protestos e conflitos com movimentos sociais e populações indígenas que culminaram na intervenção federal através de portarias que autorizaram o emprego da Força Nacional de Segurança Pública nos canteiros da obra. Essa portaria foi viabilizada pelo Decreto 5.289, emitido em de 29 de novembro de 2004 (BRASIL, 2004). Em 2013 a Força Nacional foi acionada, assim como em 2018, com o objetivo de assegurar a "incolumidade das pessoas, do patrimônio e a manutenção da ordem pública dos locais em que se desenvolvem as obras, demarcações, serviços e demais atividades" relacionadas à construção da hidrelétrica (BRASIL, 2018, p. 204).

\section{Resultados e discussão}

\section{Perfil dosACS e suas percepções acerca das atividades desenvolvidas}

A coleta de dados, realizada em 2015, obteve uma amostra de 53 ACS, composta por 36 mulheres (19 atuavam na área urbana e 17 na área rural) e 17 homens (6 da área urbana e 11 da área rural). Quanto à formação escolar, apenas $9,4 \%$ completaram o ensino superior e 5,6\% não concluíram ou ainda estavam cursando uma graduação. A maioria $(69,8 \%)$ finalizou o ensino médio e somente $1,9 \%$ não o completaram. Alguns estudaram até o ensino fundamental $(3,8 \%)$, enquanto outros não completaram esta formação $(5,7 \%)$. Ainda outros $(3,8 \%)$ alcançaram uma formação técnica relacionada à sua atuação profissional.

Quanto ao tempo de atuação como ACS, a maioria tem desempenhado suas atividades entre 10 anos (45,3\%, com pouca diferença entre rurais e urbanos) a 20 anos $(39,6 \%$, com destaque aos ACS rurais). Outros trabalhavam há menos de 1 ano $(11,3 \%)$ e alguns entre 1 a 4 anos (1,9\%). Apenas 1,9\% tinha mais de 20 anos de atuação como agente de saúde. 
Agentes comunitários de saúde no contexto da implantação de grandes obras de infraestrutura: o caso da hidrelétrica Belo Monte, Altamira-PA

\section{Reconhecimento e nível de satisfação dos ACS em relação ao trabalho}

Os resultados indicaram que a maior parte dos ACS (tanto rurais quanto urbanos) percebem que a comunidade reconhece o seu trabalho. Quanto a satisfação, verificaram-se percepções diferentes entre os que atuam em área urbana e em área rural. A maioria dos ACS rurais disseram estar totalmente satisfeitos, enquanto a maioria dos ACS urbanos responderam que estão parcialmente satisfeitos. Aqueles que estão satisfeitos parcialmente ou insatisfeitos relataram que eles deveriam: "ser enxergados como profissionais pelos nossos chefes de saúde"; "se trabalhássemos como equipe ficaria satisfeita, somos PACS"; "falta material para fazermos um trabalho de qualidade"; "embora muitas vezes não falamos a mesma língua, me sinto com certeza parte do sistema. O sistema é muito burocrático e cheio de entraves que atrapalha o desempenho do trabalho". Já a insatisfação com o salário foi quase consensual, indicando que o fator econômico (salário) não tende a ser um limitador para a satisfação pelo trabalho, principalmente para os ACS rurais. Esses dados obtidos através da aplicação do questionário são relativizados com o cotejamento dos dados obtidos através dos grupos focais onde são relatados vários problemas na execução de suas atividades cotidianas e que tendem a impactar a satisfação com o trabalho, como veremos mais adiante.

\section{Avaliação da comunidade conforme relato dos ACS}

Na percepção dos ACS, as reclamações sobre os serviços de saúde, elencados pela população, referem-se à, em ordem decrescente: não conseguirem vaga ou senha; não ter dentista; não ter médico; desistirem devido a longa espera; equipamentos não estarem funcionando; e não haver profissional especializado para atender.

Durante o grupo focal, os ACS relataram que muitas vezes os membros da comunidade perguntam sobre o Programa Bolsa Família e solicitam apoio psicológico; que eles servem como receptores das reclamações da população e que, embora eles possam escutá-las, possuem pouca capacidade para alterar a situação. As críticas do trabalho do ACS se deve, na percepção deles, "porque somos cobrados por aquilo que não acontece no serviço de saúde e por ter família que não cumpre com as nossas orientações"; "quando me pedem remédio e eu falo que não posso dar remédios, pois só posso trabalhar com a prevenção"; "nem tudo que o paciente pede a gente pode resolver, aí então eles acham que é falta de interesse do ACS”. Nessas falas aparecem as tensões entre as atribuições que 
o sistema oficial de saúde demanda aos ACS e as expectativas da população, que nem sempre coincidem.

Em relação a outras terapias ou curas que as pessoas da comunidade utilizam, as respostas seguiram um padrão bastante disseminado na sociedade brasileira. Apesar da existência de unidades de saúde espalhadas em vários bairros do município de Altamira-PA, a utilização de outras terapias (com destaque nesse caso, para as benzedeiras e uso de plantas medicinais) é uma prática relacionada à compreensão do processo de saúde-doença, por parte da população, que não abrange apenas as classificacões biomédicas, mas também as classificações culturais. Um número significativo da população encontra, através de canais heterogêneos e até antagonistas (na medicina e na religião), formas alternativas de acesso e tratamento (GRISOTTI, 1998). Os ACS rurais percebem que na área rural a comunidade a comunidade «tem sua própria ciência», sendo que uma ACS estava realizando um trabalho de identificacão da medicina tradicional para o seu trabalho de conclusão de curso de graduação.

Quanto aos problemas, conflitos e situações de riscos encontrados na comunidade, assim como os preconceitos, costumes e idéias que poderiam interferir no seu trabalho, alguns ACS relataram a violência doméstica e as dificuldades para lidar com esse problema, especialmente em que momento (e como) eles deveriam acionar instituições de apoio, sem correr o risco de perder a confiança dos responsáveis pela residência. Outra situação, ocorreu com um agente durante a campanha para o uso de preservativos: "o pai da menina me disse: vá ensinar para a tua filha, a minha deixa que eu ensino". Nessa fala é possível perceber as dificuldades relativas ao seu papel enquanto agente intermediário entre a compreensão do pai sobre do tema e as campanhas de saúde pública, e as consequentes implicações na eficácia de políticas de saúde.

Várias outras situações foram mencionadas como: "A mãe gastava o dinheiro do bolsa família com bebedeiras e não comprava os alimentos das crianças, ela era viciada. O pai me chamou para ir no conselho falar por ele, eu levei a assistente social em sua casa, etc..."; "Gravidez não esperada na adolescência e usuário de drogas, crianças fora da escola"; "Os homens não gostam de usar camisinha e tem medo de fazer exame de próstata"; "Acontece muito do ACS chegar e a família está em conflito e querer conversar e nós, ACS, sempre temos que estar pronto para escutar de ambas as partes e aconselhar tanto um quanto o outro".

A influência de ideias religiosas é comum nas pequenas comunidades gerenciadas, muitas vezes, por líderes religiosos que enfatizam determinados princípios direcionadores da vida dos membros do grupo social, e a partir disso, várias práticas são disseminadas na comunidade na percepção dos ACS: "criança com dor de cólica e a mãe fala que é quebrante"; "paciente hipertensa que se recusa a tomar medicação, pois acredita que sua religião vai curá-la"; "alguns não querem 


\section{Agentes comunitários de saúde no contexto da implantação de grandes obras de infraestrutura: o caso da hidrelétrica Belo Monte, Altamira-PA}

tomar vacinas porque dizem que fazem mal"; "idosos que não tomam remédios por causa de crendices". Os ACS ressaltaram que esses saberes e práticas podem dificultar o seu trabalho, uma vez que alguns seguidores de religiões não aceitam alguns tipos de procedimentos terapêuticos ou condutas como o uso de preservativo e a transfusão de sangue. Nota-se que os ACS analisam a comunidade com base no olhar das instruções biomédicas obtidas em seus cursos de capacitação. No entanto, como parte da comunidade, eles próprios partilham muitas vezes, saberes de cunho popular ou religioso, e os utilizam quando necessário nas visitas domiciliares.

Em relação à identificação de riscos, os ACS relataram casos nos quais a vigilância sanitária e ambiental deveria trabalhar conjuntamente: de uma família que "morava à beira de um igarapé, abaixo de uma fazenda onde um chiqueiro de porco escorria o chorume para o igarapé, o mesmo que fornecia água para beber e cozinhar os alimentos"; de outra família que "vivia perto do lixo a céu aberto e água contaminada"; e "famílias que criavam porcos perto das casas, dessa forma prejudicavam várias famílias". Além de outros casos ligados a riscos de segurança pessoal: "Quando cheguei para visitar em uma certa residência me deparei com um senhor abusando de uma pré-adolescente, fiquei com medo de denunciar, pois tinha que continuar no trabalho"; "Já tive que visitar um jovem que me assaltou e me pôs de refém por duas horas, até hoje tenho medo desse criminoso, ex-presidiário, pois é muito perigoso".

Em todos esses relatos fica evidente, mais uma vez, as tensões entre as atribuições legais do ACS e as demandas de uma população que tem nesse profissional o vínculo mais permanente e sistemático com os serviços de saúde, intensificados devido às distâncias geográficas que caracterizam o território na região amazônica. Por um lado, os serviços oficiais de saúde demandam aos ACS a promoção e educação em saúde com base nos procedimentos apreendidos nos cursos de capacitação, por outro lado, na sua atuação cotidiana esses trabalhadores se deparam com outras demandas que emergem da complexidade da vida urbana e rural que caracteriza esse território, as quais requerem uma gestão mais integrada com outros setores e profissionais e um sistema de compartilhamento e debate das informações trazidas do trabalho na comunidade ao serviço de saúde. Como destacado por Carmo e Guizardi (2017):

[...] a marca da intersetorialidade, como indutora de superação da fragmentação nas políticas sociais, orienta para uma ideia de colaboração, de complementaridade, promovendo um olhar atento às necessidades das populações, reconhecendo as particularidades de sua organização, suas formas de sobrevivência e os rebatimentos da questão social em seu cotidiano (CARMO; GUIZARDI, 2017, p. 1279). 
Porém, apesar do consenso existente sobre a necessidade do trabalho intersotorial, na prática identifica-se uma justaposição de esforços em algumas áreas e escassez de recursos em outros, diluindo a singularidade desse profissional, situado na interface intersetorial da promoção da saúde, educação e meio ambiente.

Os relatos apresentados por eles, através dos grupos focais, relativizam a declaração de satisfação no trabalho, emitida nos questionários, reforçando o que a literatura tem demarcado sobre esse tema. A falta de instrumentos e de tecnologias para suprir as necessidades de trabalho dos ACS nas diferentes dimensões propostas para sua atuação, constitui limitações que dificultam a operacionalização do seu trabalho com ênfase na integralidade do cuidado, assim como as limitações presentes no cotidiano de trabalho produzem sintomas de estresse, refletindo em sua saúde, física, psicológica e social (OLIVEIRA et al., 2010).

O não reconhecimento profissional faz com que alguns agentes sintamse desmotivados e apresentem diminuição do comprometimento com o trabalho (SANTANA et al., 2009). Guanaes-Lorenzi e Pinheiro (2016), identificaram uma tensão em torno da des/valorização de seu trabalho nas práticas discursivas dos ACS. Sentidos de valorização surgem quando destacam sua atuação próxima à comunidade e seu potencial para construção de vínculos, mas são tensionados por sentidos de desvalorização referidos a aspectos macroestruturais, como baixos salários e pouco reconhecimento de sua função se comparados a profissionais de nível superior, estabelecendo assim limitações quanto a sua autonomia e reconhecimento como profissional.

\section{Percepção dos ACS sobre as mudanças econômicas e sociais trazidas por Belo Monte}

Um estudo sobre percepções da população em torno de um tema específico e polêmico, como é o caso da usina de Belo Monte, é sempre conjuntural, ou seja, está ancorado na experiência subjetiva imediata e sujeita a modificações conforme as mudanças provocadas no processo de instalação da obra. Uma grande obra de infraestrutura como essa provocou expectativas e conflitos entre os diferentes segmentos da população.

Nessa parte do artigo, analisamos a percepção dos ACS sobre a situação dos serviços públicos e a qualidade de vida em Altamira-PA com a chegada da usina de Belo Monte (2010) em comparação com anos anteriores, especialmente em relação às categorias: emprego, violência, energia, serviços de saúde e condições de vida em geral, conforme apresentado no gráfico a seguir. 
Agentes comunitários de saúde no contexto da implantação de grandes obras de infraestrutura: o caso da hidrelétrica Belo Monte, Altamira-PA

Gráfico 1 - Percepção dos ACS Urbanos acerca das mudanças em indicadores de saúde da cidade de Altamira-PA

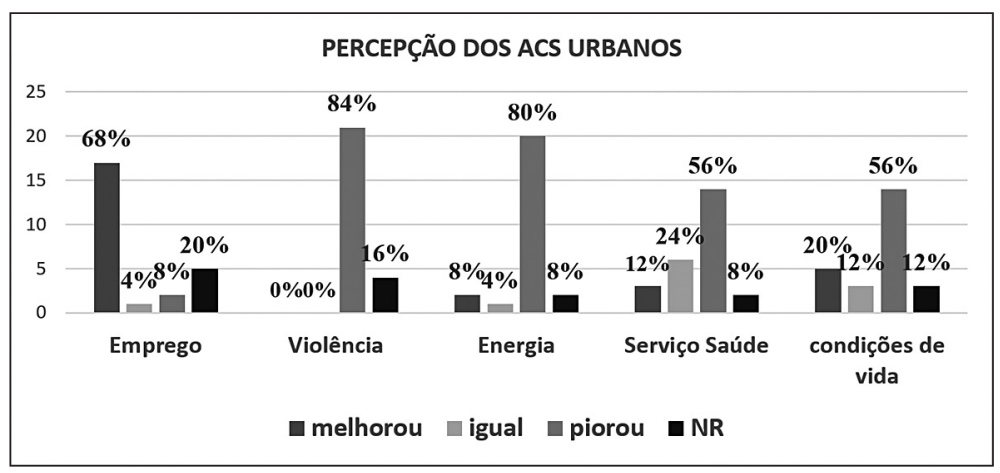

Fonte: Dados de Pesquisa. *NR= Não responderam

A geração de emprego aumentou durante a instalação da obra na percepção dos ACS, inclusive alguns deles foram trabalhar na obra devido ao salário maior, abandonando a atividade de ACS. Contudo, nos grupos focais eles questionaram a qualidade desse tipo de emprego: apesar do maior salário, percebiam que não somente a obra era temporária, mas também o próprio sistema de contratação de funcionários.

Essa percepção dos ACS encontra respaldo no estudo realizado por Conceição (2014, p. 74), o qual mostra, com base nos dados do Ministério do Trabalho e Emprego, que os constantes recrutamentos para a obra estão relacionados com as frequentes demissões realizadas pela construtora: "no período de janeiro a julho de 2013, do total de 12.289 trabalhadores contratados, 52\% foram demitidos no mesmo período". Essa situação de rotatividade foi denunciada pelos movimentos sociais da região e representou um dos aspectos concernentes às diversas greves dos trabalhadores da usina - duas em 2011, quatro em 2012 e três em 2013 (CONCEIÇÃO, 2014).

Os serviços de saúde e as condições de vida pioraram na percepção da maior parte dos ACS urbanos, e, mesmo considerando o alto número de não respondentes de ACS da área rural (ver GRÁFICO 2), a precariedade destes indicadores também foi percebida nessa categoria de agentes de saúde. Aumento populacional, aumento das filas para a comunidade ser atendida, aumento dos preços dos alimentos, aumento da insegurança pública e problemas com saneamento básico foram enfatizados pelos ACS.

O aumento populacional devido a construção de Belo Monte foi um fator mencionado principalmente pelos ACS urbanos. Relataram problemas para identificar e cadastrar os moradores e para atingir a meta de vacinação: "Brasil 
Novo conseguiu atingir a meta e Altamira não conseguiu porque houve um aumento populacional".

Um destaque na percepção dos ACS é para a categoria "violência", diante da qual $84 \%$ deles responderam que "piorou" com o advento Belo Monte. Esta percepção encontra sustentação em outros dados empíricos. Os autores do Atlas de Violência (CERQUEIRA et al., 2017), analisaram a prevalência da violência nos municípios brasileiros, e listaram aqueles com populações maiores que $100 \mathrm{mil}$ habitantes em 2015. Neste ano, a cidade de Altamira apresentou a maior taxa de homicídio por 100 mil habitantes, com valores estimados de 105,2.

Os autores destacam que, em relação aos municípios mais violentos em 2015, com mais de 100 mil habitantes, Altamira-PA lidera a lista, que tem representantes de Unidades Federativas das cinco regiões brasileiras. Para eleger Altamira-PA como o município mais violento do País foi realizada a soma das taxas de homicídios e de Mortes Violentas com Causa Indeterminada (MVCI), não restringindo a análise apenas à taxa de homicídios que poderia induzir ao um erro já que em muitos municípios o número de MVCI pode ocultar o verdadeiro nível de agressão letal por terceiros (homicídios). Também foram ressaltadas no documento as diferenças socioeconômicas entre o município menos violento (Jaraguá do Sul-SC) e o mais violento (Altamira-PA) considerando: números de residentes 164 e 108 mil, densidades demográficas de 268,8 e 0,65 habitantes por quilômetro quadrado, Índice de Desenvolvimento Humano $(\mathrm{IDH}=0,803)$ e $(\mathrm{IDH}=0,665)$ respectivamente.

As diferenças supracitadas, entre os dois municípios ilustram o papel que o estágio de desenvolvimento humano tem sobre a criminalidade violenta letal, elas não explicam tudo, afirmam os autores. Todavia, ressaltam que um crescimento rápido e desordenado das cidades (caso Altamira-PA, no rastro da construção da Usina de Belo Monte) pode ter sérias implicações sobre o nível de criminalidade local, percebido pelos ACS.

O grande aumento populacional, em curto período de tempo, e a falta de preparação do município em relação às políticas públicas para atender as novas demandas são fatores explicativos para o aumento da violência. A segurança pública não teve investimento direto vinculado às condicionantes socioambientais do licenciamento. De acordo com Assis de Oliveira (2017), pesquisador sobre violência em Altamira-PA, foi pactuado um Termo de Cooperação externo às condicionantes:

Não tem PBA de segurança pública. Ele foi feito por fora do licenciamento! [...] É só verificar em todas as condicionantes e nos documentos de licenciamento. Não aparece nada relacionado a segurança pública, apenas informação de que será feito um acordo posterior para tratar do assunto. Se a segurança pública fosse condicionante, o IBAMA deveria apresentar em cada relatório de monitoramento dados sobre ela, e nunca apresentou. (OLIVEIRA, 2017, p.13). 
Agentes comunitários de saúde no contexto da implantação de grandes obras de infraestrutura: o caso da bidrelétrica Belo Monte, Altamira-PA

Esse termo de cooperação para investimentos na área de segurança pública destinou 115 milhões para projetos e ações de segurança para os 11 municípios da área de influência, sendo que parte deste recurso foi destinado à compra de um helicóptero (35 milhões), para aluguéis de veículos (viaturas), compra de motocicletas para frotas policiais, como também reforma dos prédios dos órgãos de segurança do município; ações estas previstas no Termo de Cooperação Técnica e Financeira firmado entre a Norte Energia e Governo do Estado do Pará em maio de 2011 e aditado em 2013 para mais dois anos (PAPER BELO MONTE-DEZEMBRO, 2014 p. 15). Vale ressaltar que, com o término da obra, os contratos de aluguéis dos veículos foram rescindidos, e estes foram devolvidos, caracterizando um paliativo momentâneo e exíguo que se estendeu ao efetivo policial pois, somente em 2017 ocorreu a abertura de vagas para compor o quadro efetivo da polícia, e as vagas são remanescentes de outros concursos ofertadas em todo o estado, portanto, já existia previsão antes do empreendimento.

Outro fator de destaque, é o caso da "energia" que $80 \%$ dos ACS afirmaram ter "piorado", um contrassenso considerando que se tratava do momento de implantação da terceira maior hidrelétrica do mundo. Sobre essa questão, não há dados oficiais, todavia é possível encontrar menção nos noticiários, jornais locais e sites, manchetes com destaque às manifestações populares sobre a frequência das quedas e aumentos no valores da energia elétrica, conforme os trechos a seguir:

[...] moradores de Altamira $(\mathrm{PA})$ voltaram às ruas para reclamar das frequentes quedas de energia. [...]. Os manifestantes saíram da região central da cidade até chegar à Celpa (Centrais Elétricas do Pará). Ocuparam a sede da empresa e entregaram uma carta de reivindicação. O documento pede por investimentos nas redes de transmissão e distribuição, ampliação do quadro de funcionários da companhia, redução nas tarifas e pagamento das indenizações pelos danos causados aos usuários pela falta de energia. A população atribui as quedas de energia à sobrecarga na demanda, causada pelo aumento de habitantes na cidade, por conta da construção da UHE de Belo Monte (LEITE, 2013, n.p.).

Com o crescimento populacional em Altamira, acelerado nos últimos dois anos pelas obras da Usina Hidrelétrica de Belo Monte, aumentou também o consumo dos serviços essenciais como a energia elétrica. Mas o aumento da demanda não teria sido acompanhado por melhorias na prestação dos serviços, o que teria causado uma sobrecarga do sistema (JORNAL G1, 2013, n.p.).

No período de construção da usina Belo Monte, não houve a expansão imediata da rede de serviços de energia, mesmo com o aumento da demanda. Tal reestruturação ocorreu de forma fracionada, mediante a realocação da população nos 
reassentamentos urbanos coletivos. No GRÁFICO 2, são apresentadas as percepções dos ACS rurais.

Gráfico 2 - Percepção dos ACS Rurais acerca das mudanças em indicadores de saúde da cidade de Altamira-PA

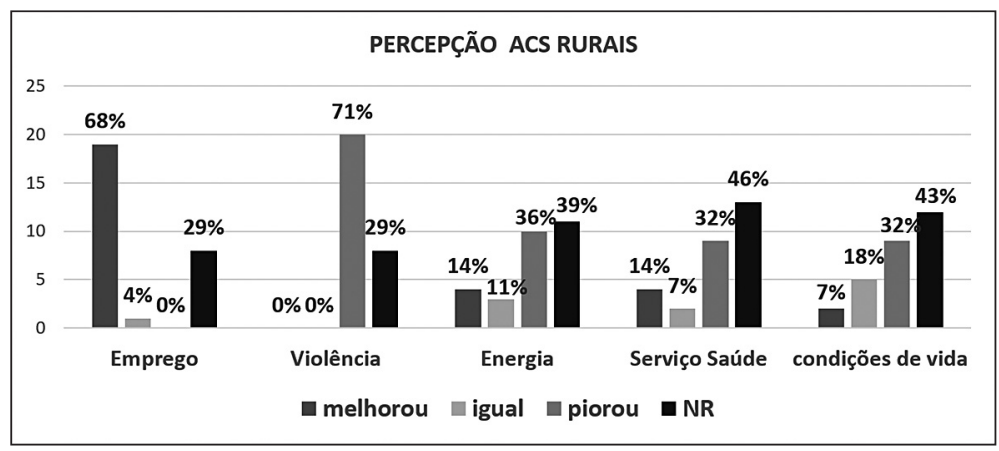

Fonte: Dados de Pesquisa. * NR= Não responderam

Os ACS rurais também destacaram o aumento do emprego e violência na zona rural, porém nos aspectos como energia, serviços de saúde e condições de vida foi elevado o número dos que não responderam, fato, que pode estar associado à existência de algumas localidades (na área rural) que ainda não dispõem de energia elétrica e à alta concentração dessas demandas na zona urbana, uma vez que esta área absorveu o maior fluxo migratório. Também pode estar relacionado com o fato do questionário, possivelmente, ter deixado alguns ACS menos abertos para exporem as suas opiniões, especialmente quando se tratava de avaliar as consequencias de um projeto de desenvolvimento que estava em andamento, as quais eles/elas teriam que lidar nas suas atividades cotidianas. Essa foi uma das razões de incluirmos dados qualitativos, obtidos através de grupos focais. Com esta técnica de investigação foi possível criar uma interação e confiança que propiciou a emergência das falas/ relatos dos problemas do exercício da profissão como foram destacadas no artigo.

Ainda assim, $32 \%$ dos ACS rurais relataram ter piorado o serviço de saúde e condições de vida na zona rural, informação que evidencia haver impacto e mudanças ocorridas também na zona rural provocada pela usina hidrelétrica de Belo Monte.

\section{Considerações finais}

Os agentes comunitários de saúde são atores importantes na vida social, não somente por representarem um elo entre os serviços de saúde e a comunidade e 
por desempenharem tarefas que extrapolam o espaço restrito das unidades básicas de saúde (já que acompanham as famílias no ambiente familiar); mas também por conviverem com mais proximidade com os dilemas sociais e psicológicos dessas famílias.

Na percepção dos ACS, a construção da UHE Belo Monte aumentou a sua rotina de trabalho em razão do grande fluxo populacional e da incapacidade de rastreamento dessa população. Embora a obra tenha aumentado, momentaneamente, o número de postos de trabalho na região, ela piorou as condições de vida principalmente dos habitantes urbanos da cidade de Altamira-PA. Aumento populacional, aumento das filas para a comunidade ser atendida, aumento dos preços dos alimentos, aumento da insegurança pública e problemas com saneamento básico foram enfatizados pelos ACS.

Os diversos estudos realizados sobre impactos de hidrelétricas na saúde humana e animal descrevem a emergência de doenças, bem como de vetores e reservatórios de doenças durante a fase de construção da barragem e após a finalização do projeto. Apesar do EIA-RIMA de Belo Monte prever esse fato, do ponto de vista prático, pouco foi realizado em função da alegada restrita disponibilidade de recursos humanos (tanto do setor público quanto do consórcio construtor) para viabilizar o processo de identificação, registro e controle de vetores e reservatórios de doenças.

Nesse aspecto, consideramos os ACS como atores chaves no processo de implantação de uma grande obra de infraestrutura como foi o caso de Belo Monte. A vinda de um enorme contingente de trabalhadores para a execução da obra, e de outras pessoas indiretamente ligadas à obra, deveria ter sido melhor planejada, entre outras formas, através de uma articulação intersetorial entre as secretarias de meio ambiente, de saúde e de obras, e de uma capacitação específica com os agentes de endemias e os ACS, os quais poderiam ter auxiliado no processo sistemático de monitoramento do fluxo populacional, na busca ativa de casos e agravos à saúde e no registro de situações que comprometam a qualidade de vida da comunidade. Esse expertise poderia viabilizar a construção de dados e indicadores de saúde que, de forma contínua e sistemática, serviriam para correlacionar as condições de morbidade antes e depois da instalação da usina; mas especialmente no momento posterior, ou seja, quando a obra estivesse concluída e, portanto, cessados os investimentos do consórcio construtor sobre a mitigação das consequências.

Para a prospeção de estratégias de futuras obras de infraestrutura, sugerimos a incorporação desses agentes de saúde no processo de identificação e mitigação dos impactos, dada a proximidade e experiência cotidiana com os problemas da cidade e seus residentes. 
Márcia Grisotti, Dinar Duarte de Vasconcelos,

Emilio Frederico Moran e Geysiane Costa e Silva

\title{
COMMUNITY HEALTH AGENTS IN THE CONTEXT OF THE IMPLEMENTATION OF A MAJOR INFRASTRUCTURE PROJECT: THE CASE OF BELO MONTE hydRoElectric POWER PLANT, Altamira-PA
}

\begin{abstract}
The aim of this article is to analyze the perception of community health agents (CHA) about the performance of their activities in the context of the implementation of Belo Monte hydroelectric power plant. This construction project intensified economic and social processes and highlighted the challenges of community work. Through focus groups and questionnaires applied to CHA in 2015, we analyzed the perception of CHA who work in the region, impacted by the construction of the dam, on: their recognition and satisfaction with their work; the identification of risky areas and of families exposed to risky events; the difficulties found during home visits and the impacts of health indicators brought by the Belo Monte project. The article intends to contribute to the improvement of future strategies and to promote the better incorporation of these agents in the process of identification and mitigation of impacts in large infrastructure projects, given the proximity and daily contact of these agents with the problems of the city and its residents.
\end{abstract}

KEYWORDS: Basic health care. Community health agents. Belo Monte Hydroelectric power plant. Perception of impacts.

\section{Agentes de salud COMUNITARIOS EN EL CONTEXTO DE LA EJECUCIÓN DE GRANDES OBRAS DE INFRAESTRUCTURA: EL CASO de la hidroeléctrica de Belo Monte, Altamira-PA}

RESUMEN: El artículo analiza la percepción de los agentes comunitarios de salud (ACS) sobre el desempeño de sus actividades en el contexto de la implementación de la Central Hidroeléctrica Belo Monte. Este proyecto intensificó los procesos económicos y sociales y destacó los desafíos del trabajo comunitario. A través de grupos focales y cuestionarios aplicados a los ACS, en 2015, analizamos la percepción de los ACS que trabajaban en la región impactada por la planta de energía, acerca: el reconocimiento y la satisfacción con su trabajo; la identificación de áreas de riesgo y familias expuestas a la situación de riesgo; las dificultades encontradas durante las visitas domiciliarias; y los impactos en los indicadores de salud traídos por el proyecto de Belo Monte. El artículo pretende contribuir en la 
Agentes comunitários de saúde no contexto da implantação de grandes obras de infraestrutura: o caso da hidrelétrica Belo Monte, Altamira-PA

propuesta de futuras estrategias que promuevan la mejor incorporación de estos agentes en el proceso de identificación y mitigación de los impactos causados por las grandes obras de infraestructura, dada su proximidad y experiencia diaria con los problemas de la ciudad y sus habitantes.

PALABRAS CLAVE: Atención sanitaria básica. Agentes de salud comunitarios. Hidroeléctrica de Belo Monte. Percepción de los impactos.

\section{AGRADECIMENTOS}

Os autores agradecem à FAPESP e ao CNPq pelo apoio financeiro recebido.

\section{REFERÊNCIAS}

AVILA, M. M. M. O Programa de Agentes Comunitários de Saúde no Ceará: o caso de Uruburetama. Ciência \& Saúde Coletiva, Rio de Janeiro, v. 16, n. 1, p. 349-360, 2011.

BRASIL. Portaria $\mathrm{n}^{\circ} 135$, de 10 de setembro de 2018. Dispõe sobre a prorrogação do emprego da Força Nacional de Segurança Pública (Força Nacional) em apoio ao Ministério de Minas e Energia, no Estado do Pará. Diário Oficial da União: seção 1, edição 176, p. 204, Ministério da Segurança Pública/Gabinete do Ministro, Brasília, DF, 12 set. 2018. Disponível em: http://www.in.gov.br/materia/-/asset_publisher/Kujrw0TZC2Mb/content/ id/40505511/do1-2018-09-12-portaria-n-135-de-10-de-setembro-de-2018-40505468. Acesso em 15 fev. 2018.

BRASIL, Lei $\mathrm{n}^{\circ} 11.350$, de 5 de outubro de 2006. Regulamenta o $\S 5^{\circ}$ do art. 198 da Constituição, dispõe sobre o aproveitamento de pessoal amparado pelo parágrafo único do art. $2^{\circ}$ da Emenda Constitucional no 51 , de 14 de fevereiro de 2006. Presidência da República, Casa Civil, Brasília, DF, 9 jun. 2006. Disponível em: http://www.planalto.gov. br/ccivil_03/_ato2004-2006/2006/lei/111350.htm. Acesso em: 15 fev. 2018.

BRASIL. Decreto ${ }^{\circ} 5289$, de 29 de novembro de 2004. Disciplina a organização e funcionamento da administração pública federal, para desenvolvimento do programa de cooperação federativa denominado Força Nacional de Segurança Pública. Presidência da República, Brasília, DF, 29 nov. 2004. Disponível em: http://www.planalto.gov.br/ ccivil_03/_Ato2004-2006/2004/Decreto/D5289.htm. Acesso em: 15 mar. 2018.

CARDOSO, F. H. Da caracterização dos regimes autoritários na América Latina. In: COLLIER, D. (Org.). O Novo autoritarismo na América Latina. Rio de Janeiro/São Paulo: Paz e Terra (Coleção Estudos Latino-Americanos, 18), p. 41-62, 1982. 
CARMO, M. E. do, GUIZARDI, F. L. Desafios da intersetorialidade nas políticas públicas de saúde e assistência social: uma revisão do estado da arte. Physis, Rio de Janeiro, v. 27, n. 4, p. 1265-1286, 2017. Disponível em : https://www.researchgate.net/publication/322923755 Desafios_da_intersetorialidade_nas_politicas_publicas_de_saude_e_assistencia_social_uma_ revisao_do_estado_da_arte. Acesso em : 23 mai. 2020.

CERQUEIRA, D.; LIMA, R. S.; BUENO, S.; VALENCIA, L. I.; HANASHIRO, O.; MACHADO, P. H. G.; LIMA, A. S. Atlas da violência 2017, Instituto de Pesquisa Econômica Aplicada - IPEA, Fórum Brasileiro de Segurança Pública, Rio de Janeiro, jun. 2017. Disponível em: http://repositorio.ipea.gov.br/handle/11058/7956. Acesso em: 15 fev. 2018.

CONCEIÇÃO, T. S. Trabalhadores nos canteiros de obras da UHE Belo Monte Altamira: condições de saúde e políticas públicas. Orientadora: Rosa Elizabeth Acevedo Marin. 2014. 193 f. Dissertação - Mestrado em Desenvolvimento Sustentável do Trópico Úmido - Núcleo de Estudos Amazônicos, Universidade Federal do Pará, Belém, 2014.

COUTO, R. C. de S.; SILVA, J. M. As questões de saúde no estudo de impacto ambiental do Aproveitamento hidroelétrico Belo Monte. In: SANTOS, S. M. B. M.; HERNANDEZ, Francisco del M. (orgs.). Painel de especialistas. Análise crítica do estudo de Impacto Ambiental do Aproveitamento Hidreleetrico de Belo Monte, 2009.

EIA - Estudo de Impacto Ambiental, Aproveitamento hidrelétrico Belo Monte. Relatório de Impacto Ambiental - Rima. Ministério de Minas e Energia, Eletrobrás, 2009.

FREITAS, L. M.; CORIOLANO-MARINUS, M. W. L.; LIMA, L. S.; RUIZ-MORENO, L. Formação dos agentes comunitários de saúde no município de Altamira (PA), Brasil. Arquivos Brasileiros de Ciência da Saúde, Belém, v. 40, n. 3, p.171-177, out. 2015.

GIONGO, C. R.; MENDES, J. M. R.; SANTOS, F. K. Desenvolvimento, saúde e meio ambiente: contradições na construção de hidrelétricas. Serviço Social \& Sociedade, São Paulo, n. 123, p. 501-522, jul./set. 2015.

GRISOTTI, M. A construção de relações de causalidade em saúde no contexto da hidrelétrica de belo monte. Ambiente \& Sociedade, São Paulo, v. 19, n. 2, p. 287-304, 2016.

GRISOTTI, M. Políticas de saúde e sistemas médicos no Brasil. Revista Katálysis, Florianópolis, SC, n. 3, p. 49-62, 1998.

GUANAES-LORENZI, C.; PINHEIRO, R. L. A (des)valorização do agente comunitário de saúde na Estratégia Saúde da Família. Ciência \& Saúde Coletiva, Rio de Janeiro, v. 21, n. 8, p. 2537-2546, ago. 2016.

HERRERA, J. A.; MOREIRA, R. P. Espacialidade do medo e insegurança pública: ensaio sobre os efeitos da UHE Belo Monte na cidade de Altamira no Pará. Revista Políticas Públicas \& Cidades, [S. l.], v. 3, n. 2, p. 2359-1552, jun. 2016. 
Agentes comunitários de saúde no contexto da implantaçấo de grandes obras de infraestrutura: o caso da hidrelétrica Belo Monte, Altamira-PA

IBGE - INSTITUTO BRASILEIRO DE GEOGRAFIA E ESTATÍSTICA. População estimada 2017: Altamira, Diretoria de Pesquisas, Coordenação de População e Indicadores Sociais, 2017. Disponível em: https://cidades.ibge.gov.br/brasil/pa/altamira/panorama. Acesso em: 15 fev. 2018.

IBGE - INSTITUTO BRASILEIRO DE GEOGRAFIA E ESTATÍSTICA. População estimada 2015: Altamira, Diretoria de Pesquisas, Coordenação de População e Indicadores Sociais, 2015. Disponível em: https://cidades.ibge.gov.br/brasil/pa/altamira/ pesquisa/1/21682. Acesso em: 15 fev. 2018.

JORNAL G1. Quedas de energia têm causado prejuízos aos moradores de Altamira. G1Globo, Altamira, 25 jul. 2013. Disponível em: http:/g1.globo.com/pa/para/noticia/2013/07/ quedas-de-energia-tem-causado-prejuizos-aos-moradores-de-altamira.html. Acesso em: 31 jan. 2018.

LEITE, L. Moradores de Altamira protestam contra as constantes quedas de energia. Instituto Socioambiental, Altamira, 30 ago. 2013. Disponível em: https://www.socioambiental.org/pt$\mathrm{br} /$ noticias-socioambientais/moradores-de-altamira-protestam-contra-as-constantes-quedasde-energia. Acesso em: 31 jan. 2018.

LETURCQ, G. Diferenças e similaridades de impactos das hidrelétricas entre o Sul e o Norte do Brasil. Ambiente \& Sociedade, São Paulo, v. 19, n. 2, abr.jun. 2016.

MACIAZEKI-GOMES, R. de C.; SOUZA, C. D.; BAGGIO, L.; WACHS, F. O trabalho do agente comunitário de saúde na perspectiva da educação popular em saúde: possibilidades e desafios. Ciência \& Saúde Coletiva, Santa Catarina, v. 21, n.5, p. 1637-1646, 2016.

MAPA DOS CAMINHOS. Condicionantes de saúde e o legado para o território. Uma análise do cumprimento de condicionantes da UHE Belo Monte relacionadas à saúde e sua efetividade para o território. Fundação Getúlio Vargas, 30 nov. 2015. Disponível em http:// indicadoresdebelomonte.eco.br/. Acesso em : 15 fev. 2018.

MORAN, E. F. Roads and Dams : Infrastructure-driven transformations in the Brazilian Amazon. Ambiente \& Sociedade, São Paulo, v. 19, n. 2, abr.jun. 2016.

MPF - MINISTÉRIO PÚBLICO FEDERAL. Recomendação MPF, 2016. Disponível em: www.mpf.mp.br/pa/sala-de-imprensa/documentos/2016/recomendacao-do-mpf-paraabertura-do-hospital-do-mutirao-em-altamira-caso-belo-monte. Acesso em: 15 fev. 2018.

NETO, J. Q. M.; HERRERA, J. A. Altamira-PA: novos papéis de centralidade e reestruturação urbana a partir da instalação da UHE Belo Monte. Confins, São Paulo, n. 28, 2016. Disponível em: https://journals.openedition.org/confins/11284. Acesso em 24 mai. 2020. 
NORTE ENERGIA. Relatório final consolidado de andamento do PBA e do atendimento de condicionantes. Brasília: NESA, 2015. Disponível em: http://licenciamento.ibama.gov.br/ Hidreletricas/Belo\%20Monte/Relatorios\%20Semestrais/7\%C2\%BA\%20RC\%20FINAL\%20 11.02.2015\%20-\%20PDF/Cap\%C3\%ADtulo\%202/7/7.4/Texto/CAP\%202\%20-\%207.4.pdf. Acesso em: 15 fev. 2018.

O'DONNELL, G. Modernization and Bureaucratic-Authoritarianism: Studies in South American Politics. Berkeley, CA. US: Institute of International Studies, 1973.

OLIVEIRA, A. C. Belo monte: violências e direitos humanos. 1 ed. Belém: Editora Supercores, 2017.

OliVeirA, A. R.; ChaVes, A. E. P.; NOGUEIRA, J. A.; SÁ, L. D.; COLlet, N. Satisfação e limitação no cotidiano de trabalho do agente comunitário de saúde. Revista Eletrônica de Enfermagem, Goiânia, GO, v. 12, n. 1, p. 28-36, 2010. Disponível em: https:// revistas.ufg.br/index.php/fen/article/view/9511. Acesso em: 23 mai. 2020.

PAPER BELO MONTE. UHE Belo Monte, Norte Energia, dezembro, 2014. Disponível em: http://norteenergiasa.com.br/site/wp-content/uploads/2015/01/PAPER-BELO-MONTEDEZEMBRO.pdf. Acesso em:12 fev. 2018.

PBA - Plano Básico Ambiental. Aproveitamento Hidrelétrico (AHE) Belo Monte. Norte Energia, CNEC, Worley Parsons, LEME Engenharia, jul. 2010. Disponível em: http:// licenciamento.ibama.gov.br/Hidreletricas/Belo\%20Monte/PBA. Acesso em: 15 fev. 2018.

SANTANA, J. C. B.; VASCONCELOS, A. L.; MARTINS, C. V.; BARROS, J. V.; SOARES, J. M.; DUTRA, B. S. Agente comunitário de saúde: percepções na estratégia saúde da família. Cogitare Enfermagem, Curitiba, PR, v. 14, n. 4, out./dez. 2009.

SCHWARTZMAN, S. Bases do autoritarismo brasileiro. Rio de Janeiro: Campus, 1982.

Recebido em 16/05/2019.

Aprovado em 11/01/2020. 